\title{
¿Observations of Increased Cloud Cover over Irrigated Agriculture in an Arid Environment $\mathscr{0}$
}

\author{
LUIS GARCIA-CARRERAS \\ School of Earth and Environment, University of Leeds, Leeds, United Kingdom \\ JOHN H. MARSHAM \\ School of Earth and Environment, University of Leeds, and National Centre for Atmospheric Science, Leeds, United Kingdom \\ DOMINICK V. SPRACKLEN \\ School of Earth and Environment, University of Leeds, Leeds, United Kingdom
}

(Manuscript received 26 August 2016, in final form 2 May 2017)

\begin{abstract}
Irrigated agriculture accounts for $20 \%$ of global cropland area and may alter climate locally and globally, but feedbacks on clouds and rainfall remain highly uncertain, particularly in arid regions. Nonrenewable groundwater in arid regions accounts for $20 \%$ of global irrigation water demand, and quantifying these feedbacks is crucial for the prediction of long-term water use in a changing climate. Here, satellite data are used to show how irrigated crops in an arid environment alter land surface properties, cloud cover, and rainfall patterns. Land surface temperatures (LSTs) over the cropland are 5-7 K lower than their surroundings, despite a lower albedo, suggesting that Bowen ratio is strongly reduced (and latent heat fluxes increased) over the irrigated cropland. Daytime cloud cover is increased by up to $15 \%$ points (a relative increase of $60 \%$ ), with increased cloud development in the morning and a greater afternoon peak in cloud. Cloud cover is significantly correlated with interannual variations in vegetation and LST. Afternoon rainfall also appears to be enhanced around the irrigation. The cloud feedback is the opposite of what has been previously observed in tropical and semiarid regions, suggesting different processes drive land-atmosphere feedbacks in very dry environments. Increased cloud and rainfall, and associated increases in diffuse radiation and reductions in temperature, are likely to benefit vegetation growth. Predictions of changes in crop productivity due to climate change and the impacts of global land-use change on climate and the use of water resources would therefore benefit from including these effects.
\end{abstract}

\section{Introduction}

Land-use and land-cover change (LULCC) alters the surface energy budget by modifying roughness, albedo, and the partitioning of incoming solar radiation into sensible and latent heat fluxes (Pielke et al. 2011),

¿ Denotes content that is immediately available upon publication as open access.

Supplemental information related to this paper is available at the Journals Online website: http://dx.doi.org/10.1175/JHM-D-160208.s1.

Corresponding author: L. Garcia-Carreras, 1.garcia-carreras@ leeds.ac.uk representing a potentially large source of anthropogenic climate change, locally and globally. Expansion of agriculture has been the dominant cause of global LULCC, with croplands and pasture now covering over a third of the Earth's ice-free land surface (Ramankutty et al. 2008). Irrigated land accounts for $20 \%$ of this global cropland area (Döll and Siebert 2002) but $40 \%$ of global food production (Abdullah 2006). Agricultural activity in very arid regions can be sustained by using nonrenewable groundwater reservoirs for irrigation (Mekonnen and Hoekstra 2011), substantially altering land surface properties and

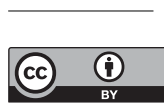

This article is licensed under a Creative Commons Attribution 4.0 license (http://creativecommons. org/licenses/by/4.0/). 
potentially local weather. Nonrenewable groundwater use tripled over the period 1960-2000 and accounted for $20 \%$ of global irrigation water demand in the year 2000 (Wada et al. 2012). Further increases in irrigated agriculture are projected in the future (Tilman 2001), which, combined with projected increases in temperatures and drought frequency (Sheffield and Wood 2008; Dai 2013), will increase the pressure on scarce water resources in arid regions (Chowdhury et al. 2013). Understanding impacts of irrigation in arid regions via land-atmosphere feedbacks is crucial for the development of climate adaptation, climate mitigation, water use, and agricultural strategies.

Land-cover change results in changes to surface properties that can alter cloud cover and rainfall, but the sign and magnitude of this feedback is highly uncertain. In tropical and semiarid regions there is evidence that, at regional scales, a moister, cooler vegetated surface (e.g., over forest or irrigated crops) has a positive feedback that enhances rainfall over, or even several hundreds of kilometers downwind of, the vegetation (DeAngelis et al. 2010; Puma and Cook 2010; Harding and Snyder 2012; Spracklen et al. 2012; Spracklen and Garcia-Carreras 2015). However, high-resolution studies that take into account realistic patterns of LULCC (which are typically at scales of tens of kilometers) have shown that horizontal gradients in surface properties are often critical and may result in a negative vegetation-rainfall feedback. Remote sensing observations have shown that enhanced clouds and rainfall occur over less vegetated (warmer and drier) surfaces with reduced rain over vegetated or irrigated land (Sato et al. 2007; Wang et al. 2009; Knox et al. 2011; Alter et al. 2015). While mesoscale and large-eddy simulations have been able to reproduce these feedbacks (Roy 2009; Garcia-Carreras and Parker 2011), these detailed interactions are missing in climate models (Taylor et al. 2012), introducing a large source of uncertainty in our ability to predict the impacts of LULCC in a changing climate.

While past studies have mainly focused on tropical or semiarid regions (e.g., Kawase et al. 2008; Douglas et al. 2009; Alter et al.2015), here we use satellite data to explore, for the first time, the impacts of irrigated agriculture on local clouds and rainfall in an extremely arid region. The evolution of the boundary layer is driven primarily by surface fluxes, and any changes in surface properties, such as soil moisture, will change the coupling by altering the proportion of sensible and latent heat fluxes (driving boundary layer deepening and moistening, respectively). The boundary layer structure in arid environments is very distinct, as it can be very deep ( $>5 \mathrm{~km}$, thus allowing cloud formation), but is capped by a very small temperature inversion (Garcia-Carreras et al. 2015). The particular structure of desert boundary layers makes them particularly sensitive to small changes in surface properties (Marsham et al. 2008; Huang et al. 2009), but it is unclear how this affects land-atmosphere couplings. Any feedbacks between irrigated land and clouds or rainfall in arid regions will also alter surface temperatures and radiation, affecting both crop productivity and crop water requirements, which will affect the long-term management of limited water resources. Beyond agriculture, there are a number of revegetation projects with the aim of combatting desertification, such as the ongoing Three Norths Forest Shelterbelt Program in China (Wang et al. 2010) or the planned Great Green Wall for the Sahara and Sahel Initiative (Woodfine and Jauffret 2009). The long-term survivability of the planted vegetation in these projects is still an open question (Cao 2008) and will depend partly on the large-scale synoptic variability (which can impose constraints on what surface conditions are viable), as well as atmospheric changes caused by the revegetation itself.

Since the 1990s there has been a rapid development of agriculture in the arid Al-Jowf region of northern Saudi Arabia. Crops are fed by nonrenewable fossil groundwater, which is not replenished by the very low rainfall amounts in the region. The Al-Jowf region therefore provides a useful test case, as the presence of vegetation is unrelated to rainfall amounts, and the crops have existed for over a decade. In this study we focus on the use of satellite data to determine if and how crops alter cloud and rainfall patterns in an arid environment. Section 2 summarizes the observational datasets used, and section 3 describes the land surface and synoptic conditions in the study region (section 3a), as well as the effects of the land surface conditions on surface properties (section 3b), clouds (section 3c), and rainfall (section 3d). Section 4 summarizes and discusses the implications of the results.

\section{Satellite datasets}

\section{a. Surface properties}

Surface conditions are described using data from the Moderate Resolution Imaging Spectroradiometer (MODIS) instruments aboard the Terra and Aqua spacecraft, which have a sun-synchronous orbit with daily overpasses at $\sim 1030$ and $\sim 1330$ local time (LT), respectively. To describe the extent of vegetation, and its temporal variability, we use leaf area index (LAI) product MODIS/Terra LAI/fraction of photosynthetically active radiation (FPAR) 8-day L4 global 1-km sinusoidal (SIN) grid (MOD15A2), which uses cloud-masked radiance data as well as the MODIS Land Cover product. The dataset used here is described in Yuan et al. (2011) and takes the MOD15A2 product and uses a modified temporal spatial filter to fill in gaps and process low-quality data, while a TIMESAT Savitzky-Golay filter is then used to generate the final dataset. The data have a resolution of 8 days and 
$1 \mathrm{~km}$ and are available for the period 2000-15. The shortwave white-sky albedo is taken from the MCD43C3 product, which combines data from both Terra and Aqua satellites (Schaaf et al. 2002; Schaaf and Wang 2015). The data are produced operationally at 500-m and 8-day resolution and are aggregated to monthly values on a $0.05^{\circ}$ grid. Land surface temperature (LST) is taken from the MODIS/Terra LST/Emissivity Monthly L3 Global $0.05^{\circ}$ climate modeling grid (MOD11C3) and MODIS/Aqua LST/Emissivity (MYD11C3) products, which use a viewangle-dependent, split-window algorithm (Wan 2014; Wan et al. 2015a,b).

\section{b. Cloud cover}

We use fractional cloud cover data from the Satellite Application Facility on Climate Monitoring (CM SAF) Cloud Property Dataset using the Spinning Enhanced Visible and Infrared Imager (SEVIRI), edition 2 (CLAAS-2), retrieval (Finkensieper et al. 2016). These data rely on visible and infrared channels and are independent of the data used to derive LAI, LST, and albedo (which are based on a different satellite). Retrieving a cloud mask with visible data over deserts is challenging because the high surface albedo makes it harder to distinguish it from clouds. This particular retrieval, however, has been shown to have good skill when compared to surface observations over the case study region (Reuter et al. 2009), and more recently when comparing a different retrieval based on SEVIRI data with aircraft observations over the Sahara (Kealy et al. 2017). These data are provided as monthly averages on a $0.05^{\circ}$ resolution grid $(\sim 5 \mathrm{~km})$ for the years $2004-15$, split between daytime only, nighttime only, and all day. Monthly-mean diurnal cycles with hourly data are also provided on a coarser grid of $0.25^{\circ}$ resolution over the same time period.

For comparison we also present results from the MODIS instruments (see section 2a). As the monthlymean cloud cover dataset is released only with a resolution of $1^{\circ}$, which is too coarse for our purposes, we show here higher-resolution data $\left(0.1^{\circ}\right.$ resolution, monthly values $)$ that are released primarily for visualization purposes with the following caveat: "The values that these files contain have been scaled and resampled for visualization purposes in NEO [NASA Earth Observations] and should not be considered for rigorous scientific examination. At best they are useful for basic analysis and trend detection." We use these data only for a basic comparison of the multiyearmean cloud cover with the SEVIRI cloud fraction.

\section{c. Rainfall}

Two rainfall datasets are used. The first is the Tropical Rainfall Measuring Mission (TRMM) product 3B42
(Huffman et al. 2007), which combines microwave data from multiple satellites and fills gaps in time and space with calibrated infrared data. The final product is then scaled to match monthly data from surface rain gauges (including some within the domain discussed in section $3 \mathrm{a}$ ). The second is the CPC morphing technique (CMORPH) retrieval, which uses the same satellite microwave data as TRMM, but fills in the spatial and temporal gaps using cloud-level motion vectors derived from infrared data, as opposed to infrared rainfall estimates. Both datasets have a 3-hourly and $0.25^{\circ}(\sim 25 \mathrm{~km})$ resolution and are available for the years 1998-2016 (TRMM) and 2002-16 (CMORPH).

\section{Results}

\section{a. Overview of the study area}

The area of focus in this study centers on an agricultural area in the Al-Jowf region in northern Saudi Arabia $\left(\sim 30^{\circ} \mathrm{N}, 38.5^{\circ} \mathrm{E}\right)$, which can be identified from the high LAI values in Fig. 1a. Note that the light green regions throughout the domain in Fig. 1 (LAI < 0.15) are not associated with any vegetation, but instead correspond to bare rock or soil albedo features, as inferred by visually inspecting visible satellite imagery. Over the agricultural region, mean LAI values are up to 0.8 , although this value includes periods where crops are not grown or lie fallow. Agriculture in this area was first established in the early 1990 s, with a rapid expansion in the early 2000s reaching a maximum cultivated area of $1600 \mathrm{~km}^{2}$ [data from General Authority for Statistics (2012); Fig. 1b]. Crops in this region are predominantly wheat, accounting for $30 \%-40 \%$ of national production (for the period 2005-09; Chowdhury et al. 2013). The large patch of agricultural land $(\sim 60 \mathrm{~km} \times 60 \mathrm{~km})$ is made up of circular fields of $\sim 1 \mathrm{~km}$ in diameter that are irrigated with nonrenewable groundwater using centerpivot irrigation systems. Rainfall in the region is very low at approximately $56 \mathrm{mmyr}^{-1}$ (Almazroui et al. 2012) and has a minimal contribution to agriculture (Alkolibi 2002).

The cropland lies in a flat, low-lying region (500-600 m MSL), surrounded by higher terrain in the northeast and southwest ( $\sim 900$ and $1200 \mathrm{~m}$ MSL, respectively; contours in Fig. 1a). Mean low-level atmospheric flow is northwesterly turning to northerly farther south, running approximately parallel to the contour lines. Any cloud or rainfall over the vegetated region can therefore not be simply attributed to orographic effects.

The time series of LAI shows that the cropland area is already well established from the start of the time period covered by the LAI data (2000-15). It is worth noting that although the absolute values of LAI may appear 
(a)
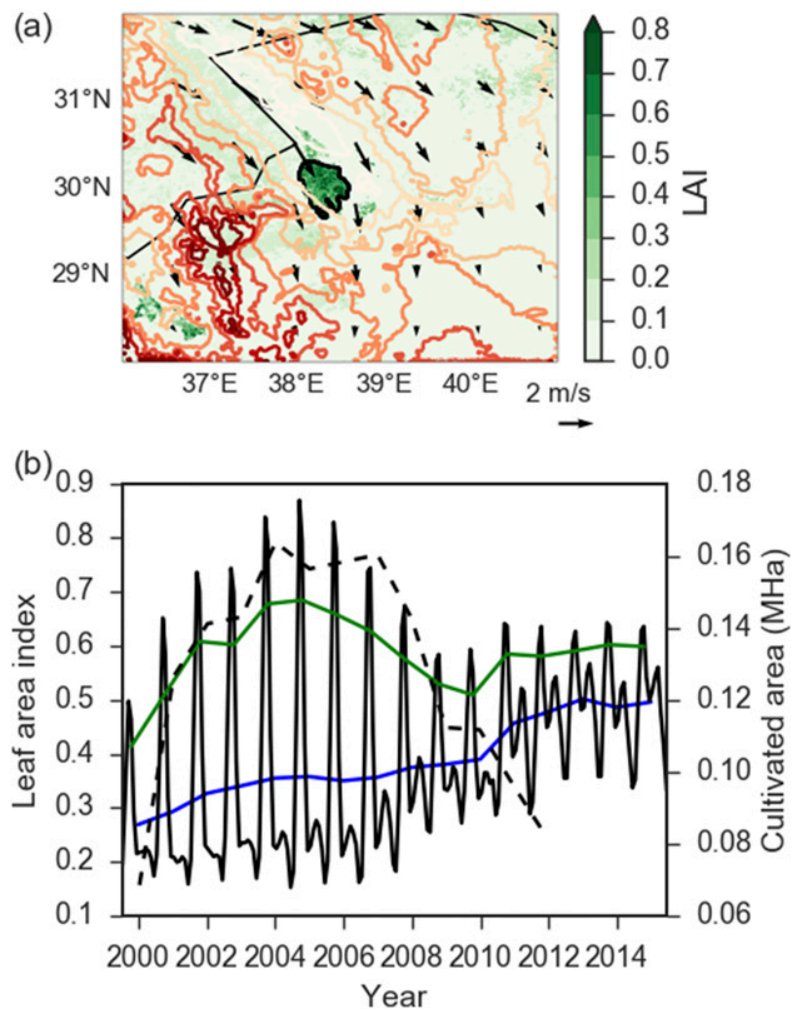

FIG. 1. (a) The mean 2000-15 LAI (shading), topography (contours with $100-\mathrm{m}$ interval from $550 \mathrm{~m}$ in yellow to $1150 \mathrm{~m}$ in red), and ERA-Interim 925-hPa wind vectors; and (b) LAI monthly (black), yearly (blue), and MAM averages (green) within the black contour in (a), and cultivated area in the region (dashed line).

low $(<1)$, these represent spatial and temporal averages that will include some fallow fields, as well as gaps between the individual circular fields. The yearly averaged LAI (Fig. 1b, blue line) shows a near-constant upward trend. There is, however, a shift in the seasonal cycle. Before 2007, LAI has one main yearly peak in spring [March-May (MAM)], suggesting a single growing season per year. After 2007, however, there is an increase in autumn LAI [September-November (SON)], leading to a bimodal distribution in LAI. This leads to the upward trend in the yearly averaged LAI throughout the period, despite the fact that maximum monthly LAI values peak in 2004-06, consistent with the reported cultivated area.

Unless otherwise stated, the subsequent analysis will focus on the MAM period, as at this time the LAI perturbation is strong throughout the period where data are available (2004-15 for SEVIRI cloud and 1998-2016 for TRMM rainfall). Particularly for rainfall, the low mean amounts and scarcity of events means that long time averages need to be used to sample enough events to derive statistically significant results, so the rest of the year, when LAI has increased only since 2007 , is not considered.

\section{b. Surface properties}

The land surface type can affect surface fluxes primarily via changes in albedo, which control the total amount of energy absorbed at the surface, and Bowen ratio, which controls the partitioning between sensible and latent heat fluxes. While vegetation typically has a lower albedo compared to bare soil, here we find that the cropland does not represent a particularly clear albedo feature in the area (Fig. 2a). The spatial variability is dominated, on the other hand, by a transition from lower albedo in the west of the domain to higher albedo in the east. The albedo pattern roughly follows the shape of the topography (Fig. 1a), consistent with higher regions being made up of darker rock, relative to the sandier and brighter eastern part of the domain (also confirmed by visual inspection of Google Earth imagery, not shown).

With the exception of the cropland, the land surface temperature pattern largely matches the albedo, with LSTs about $5 \mathrm{~K}$ higher over areas of low albedo $(\sim 0.2)$ relative to areas of high albedo $(\sim 0.4$; Figs. $2 \mathrm{~b}, \mathrm{c})$. The magnitudes of these values are consistent with aircraft observations over variable albedo features in the Sahara (Marsham et al. 2008) and are unsurprising when one considers that the majority of the surface fluxes will be converted to sensible heating over such a dry land surface. The cropland, however, is $5-7 \mathrm{~K}$ cooler than its immediate surroundings, despite having a lower albedo, implying that the increases in total surface fluxes over the cropland are more than compensated by large reductions in sensible heat fluxes (and associated increases in latent heat fluxes), as would be expected from the presence of irrigation in a dry environment (e.g., Kueppers and Snyder 2012). The rougher surface over the cropland relative to the desert could also contribute to the reduction in LST, but is unlikely to be the primary driver of such a large LST anomaly. The reduction in LST over the cropland will also be associated with a decrease in boundary layer height, which for any given initial profile will depend on the surface sensible heat fluxes.

It is possible to estimate the expected impact of the surface conditions shown in Fig. 2 on the boundary layer equivalent potential temperature $\theta_{e}$, which will control the buoyancy of saturated air rising in a convective cloud. An increase in $\theta_{e}$ in the boundary layer will increase the convective available potential energy (CAPE) for that air. The $\theta_{e}$ flux into the boundary layer depends on the total surface fluxes (Betts and Ball 1995), which are in turn a function of albedo. The boundary layer $\theta_{e}$, however, will also depend on the boundary layer depth; in a deeper boundary layer the $\theta_{e}$ flux enters a larger volume (reducing its effect on boundary 
(a)
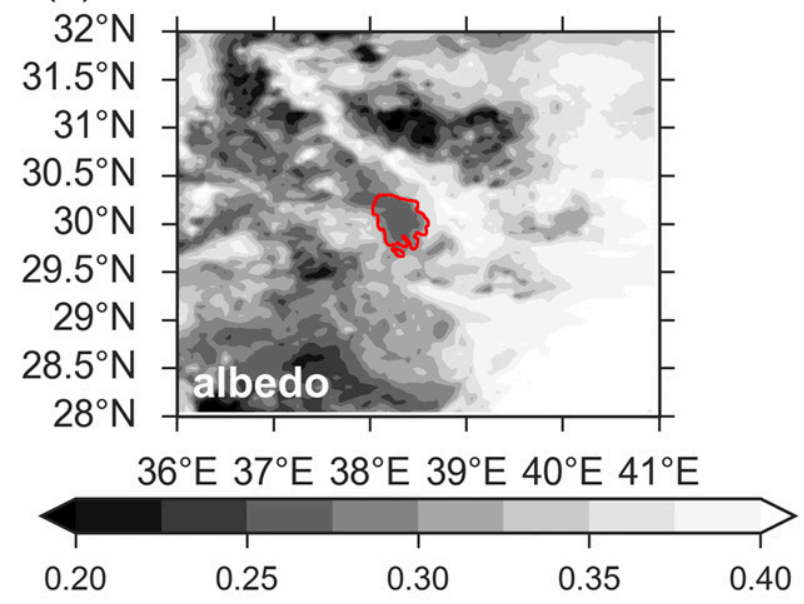

(b)

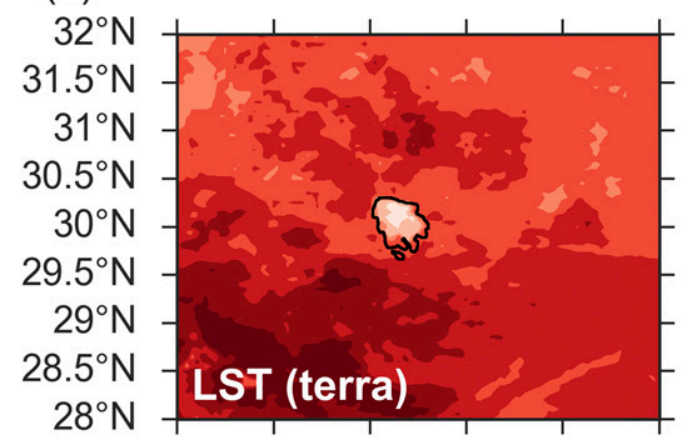

$36^{\circ} \mathrm{E} 37^{\circ} \mathrm{E} 38^{\circ} \mathrm{E} 39^{\circ} \mathrm{E} 40^{\circ} \mathrm{E} 41^{\circ} \mathrm{E}$

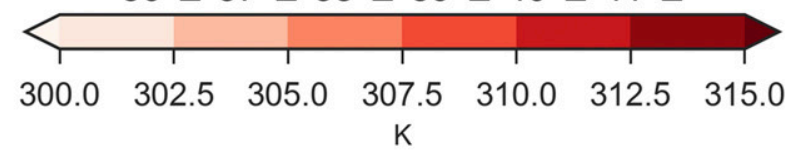

(c)

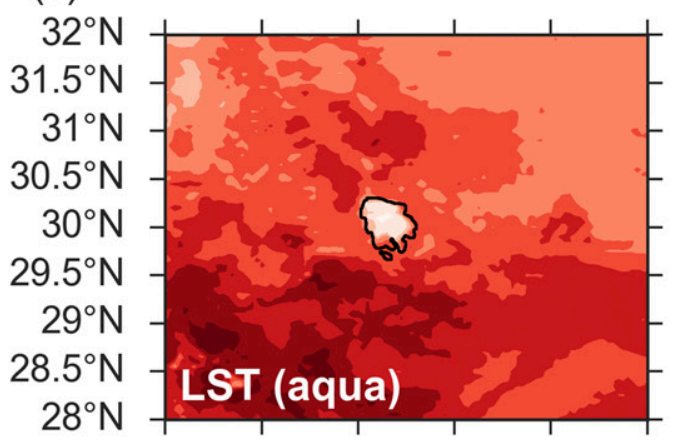

$36^{\circ} \mathrm{E} 37^{\circ} \mathrm{E} 38^{\circ} \mathrm{E} 39^{\circ} \mathrm{E} 40^{\circ} \mathrm{E} 41^{\circ} \mathrm{E}$

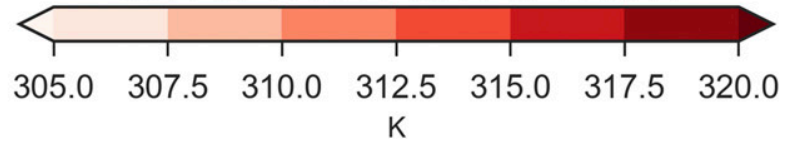

FIG. 2. Mean MAM (a) albedo and LST at (b) 1030 LT and (c) 1330 LT. Data were available for $2000-15$ for (a) and (b) and 2002-15 for (c). layer $\theta_{e}$ ), and the boundary layer growth itself will have occurred by entraining more (typically low $\theta_{e}$ ) freetropospheric air. These factors mean that the same $\theta_{e}$ flux will lead to larger $\theta_{e}$ increases in cooler, shallower boundary layers, as found in observations (Betts and Ball 1995) and large-eddy simulations (Garcia-Carreras et al. 2011). Over the cropland we therefore expect a relatively high $\theta_{e}$ flux (due to its lower albedo) and a high impact of this flux on the boundary layer $\theta_{e}$ (due to the shallower boundary layer).

In summary, while we have no in situ observations to show how the irrigated cropland is altering the atmospheric profile, the combination of relatively low albedo and greatly reduced LSTs should be associated with a cooler, moister, and therefore shallower boundary layer, with higher boundary layer $\theta_{e}$.

\section{c. Mean cloud cover}

Mean MAM cloud fractions across the domain (excluding the cropland region) have a northeastsouthwest gradient, varying between $22 \%$ and $32 \%$ in the full day average (Fig. 3a). In the northern part of the domain clouds are least frequent in the lower-lying areas (centered at $31.5^{\circ} \mathrm{N}, 38^{\circ} \mathrm{E}$ ). Daytime cloud cover is higher than at night, particularly north of $\sim 30.5^{\circ} \mathrm{N}$ (Figs. 3b,c).

Embedded within the large-scale pattern, there is a clear peak in cloudiness over the cropland area that occurs only during the day (Fig. 3). Maximum cloud cover values over the cropland reach $40 \%$ during the day, while cloud cover at the same latitude outside the cropland area averages $\sim 25 \%$, representing a relative increase of up to $60 \%$. The very close spatial match between cloud cover frequency and the cropland region, as well as the fact that the enhancement occurs only during the day when land-atmosphere interactions are expected to occur, provides strong evidence that the presence of the crops is the cause of the enhanced cloud frequency. Cloud mask retrievals based on SEVIRI data have been found to have good skill over deserts (Kealy et al. 2017; Reuter et al. 2009), but satellite detection of clouds over a bright surface remains a challenge. Comparing a dark, vegetated surface with a bright desert surface could therefore potentially introduce systematic biases. The albedo values, however, show that the cropland is not anomalously dark compared to other regions within the domain containing darker rocks, and so it is unlikely that albedo-related biases can explain the cloud cover results. Cloud fraction data from the MODIS satellite, which is only released at the highest spatial resolutions $\left(0.1^{\circ}\right)$ for visualization purposes, is also consistent with the SEVIRI data (Fig. 4). There are other controls that will determine the location of clouds 
(a)

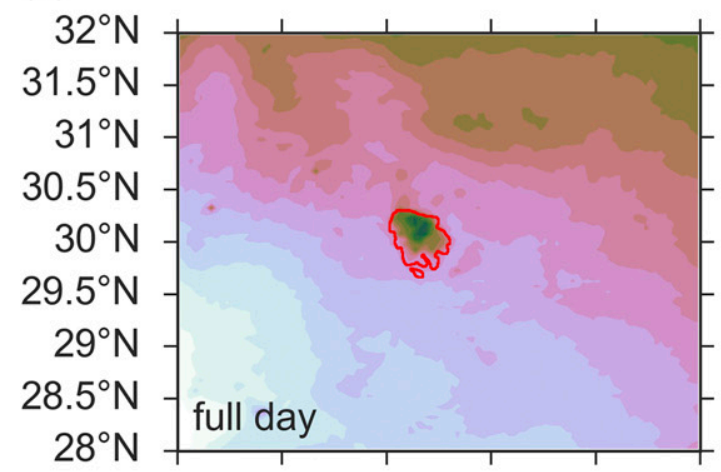

$36^{\circ} \mathrm{E} 37^{\circ} \mathrm{E} 38^{\circ} \mathrm{E} 39^{\circ} \mathrm{E} 40^{\circ} \mathrm{E} 41^{\circ} \mathrm{E}$

(b)

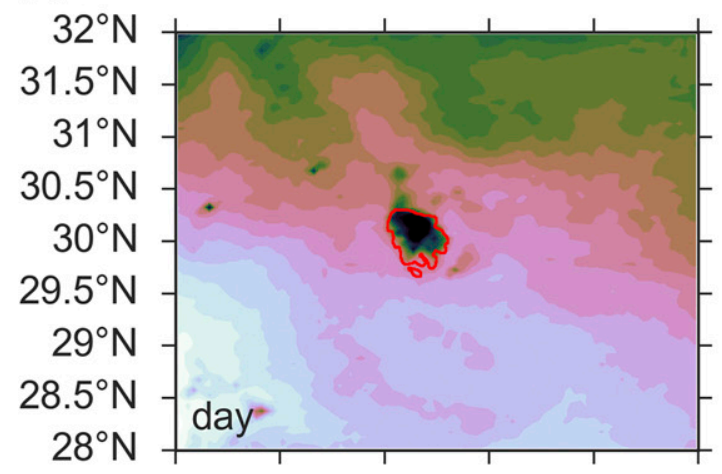

$36^{\circ} \mathrm{E} 37^{\circ} \mathrm{E} 38^{\circ} \mathrm{E} 39^{\circ} \mathrm{E} 40^{\circ} \mathrm{E} 41^{\circ} \mathrm{E}$

(c)

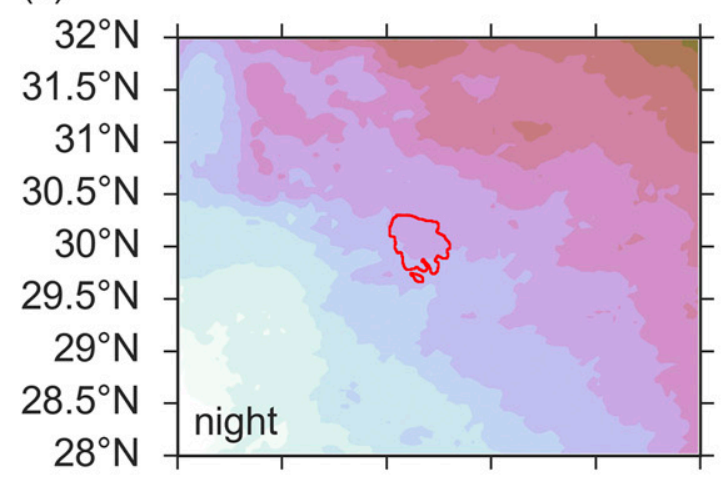

$36^{\circ} \mathrm{E} 37^{\circ} \mathrm{E} 38^{\circ} \mathrm{E} 39^{\circ} \mathrm{E} 40^{\circ} \mathrm{E} 41^{\circ} \mathrm{E}$

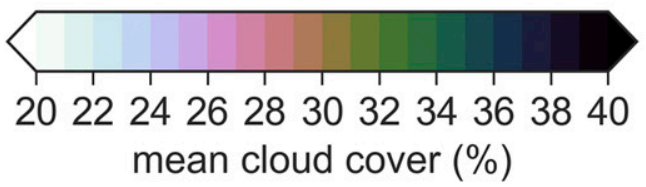

FIG. 3. Mean MAM cloud cover from SEVIRI for 2004-15 for (a) all times, (b) daytime only, and (c) nighttime only. The red contour shows the boundary of the cropland region. on any given day, so the impact of the cropland on the mean cloud cover will not necessarily be apparent in single satellite images. We have included, however, some examples in the supplemental material (Fig. S1) of single days where clouds appear to be enhanced, or forming preferentially, over the cropland, although generally these are embedded within more complex larger-scale cloud patterns.

The diurnal cycle in cloud cover shows a midafternoon (1400-1600 LT) peak in cloud cover in the area surrounding the cropland, defined as a $25-\mathrm{km}$-wide strip surrounding the crops (Fig. 5, blue line), and this pattern is representative of the rest of the domain (not shown). This is consistent with about half of the cloud cover being associated with boundary layer clouds forming once the boundary layer has had time to fully develop. Cloud cover over the cropland is the same as its surroundings between 1700 and 0700 LT, but then increases much more rapidly in the early morning relative to its surroundings, reaching close to its maximum value by $1100 \mathrm{LT}$. The cloud cover difference over the cropland is $\geq 10 \%$ higher in absolute terms compared to its surroundings between 1000 and 1400 LT, representing up to a $50 \%$ relative increase (at $1100 \mathrm{LT}$ ). This is significant as the largest differences occur when solar insolation is strongest, and so when the impact of cloud on surface radiation is greatest. The MODIS cloud cover at 1030 (Fig. 4a) and 1330 LT (Fig. 4b) shows similar magnitudes over the cropland, but much lower values around the cropland at 1030 compared to $1330 \mathrm{LT}$, consistent with the mean diurnal cycle from SEVIRI.

Further evidence of the land-atmosphere coupling is provided by the significant correlation between interannual variations in seasonal LAI and seasonal cloud enhancement over the crop across all seasons $(r=0.66$, $p<0.01$; Fig. 6a). In the MAM period, LAI values have been consistently high (leading to consistently enhanced cloud), but the results from the other seasons show the degree to which LAI change can alter cloud cover. This means that as cropping practices change (e.g., as seen with the increase in summer and autumn LAI from 2008; Fig. 1b), the seasonal cycle in cloud cover will be altered as well.

The sensitivity of cloud cover to changes in LAI appears to vary depending on season, with higher sensitivity during the summer months [June-August (JJA)] compared to both spring and autumn (MAM and SON; Fig. 6a). The impact of LAI on cloud is mediated by changes in LST, which has a much higher correlation with cloud $(r=-0.88, p<0.01$; Fig. $6 c)$ compared to albedo $(r=0.29, p<0.05$; Fig. 6b). As discussed in section $3 \mathrm{~b}$, changes in LST are evidence of changes in Bowen ratio, and so it is likely that the combination of 
(a)

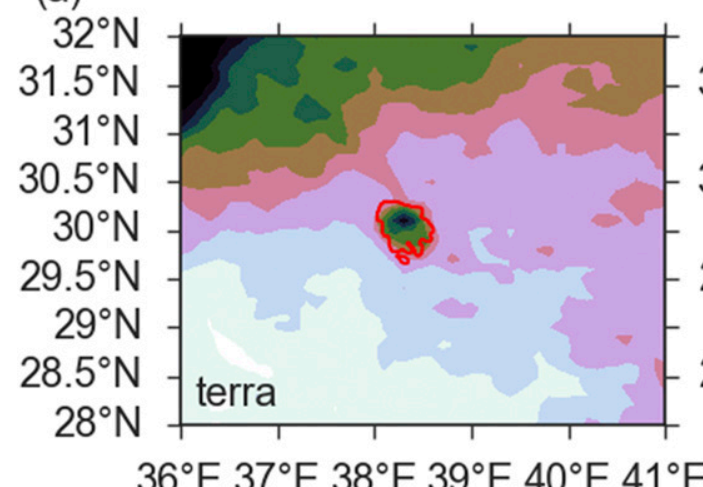

(b)

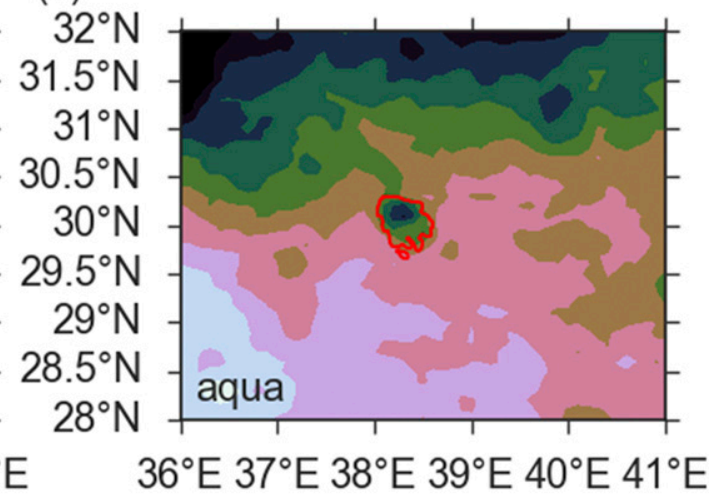

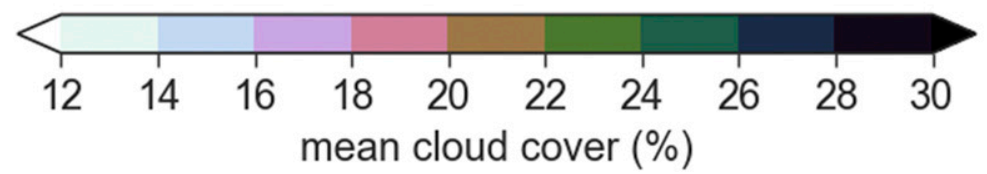

FIG. 4. Mean MAM cloud cover from MODIS for (a) the Terra satellite (1030 LT, 2000-16) and (b) the Aqua satellite (1330 LT, 2002-16).

lower temperatures and higher moisture flux are leading to enhanced cloud. Unlike with LAI, the relationship between LST and cloud cover is independent of season, which suggests that the higher sensitivity to LAI in summer is due to enhanced evaporation from the vegetation when conditions are warmer and/or drier.

\section{d. Mean rainfall}

Compared to clouds, rainfall is a much rarer event, with $\sim 1 \%$ of days registering more than $1 \mathrm{~mm}$ on any given TRMM pixel in the domain (not shown). Because of the scarcity of rainfall events, here we only analyze the MAM period, when LAI values were high for all the years. Rainfall in the domain peaks in the afternoon (1400 LT), although some rainfall occurs throughout the night. In both datasets the mean MAM rainfall in the domain has an east-west gradient, although in TRMM the highest rainfall amounts are in the northeast, both in the afternoon (1400-1700 LT) and at night (2300-0700 LT; Figs. 7a,b), while in CMORPH the highest values are in the southeast, again over higher terrain (Figs. 8a,b).

Embedded within the larger-scale east-west gradient there is a peak in afternoon rainfall in the area over and around the cropland (Figs. 7a, 8a), which is not apparent at night (Figs. 7b, 8b), consistent with a land-surfaceinduced forcing. While at such small scales (relative to the dataset resolution) there are differences between the two datasets, this peak in the middle of the domain is apparent in both and seems to be independent of the larger-scale pattern in rainfall. Given the coarser spatial resolution of the data compared to cloud cover, and the low rainfall amounts in the region, it is difficult to determine, however, whether rainfall is actually enhanced over the cropland itself (as with cloud cover), or over the boundaries (as observed in other regions). Separating the mean rainfall into the mean rainfall intensity when it does rain (Figs. 7c, 8c) and the percentage of rainy days (Figs. $7 \mathrm{~d}, 8 \mathrm{~d}$ ) suggests there is some contribution from both, but more detailed analysis of the mechanisms at work are hampered by the low number of rainfall events.

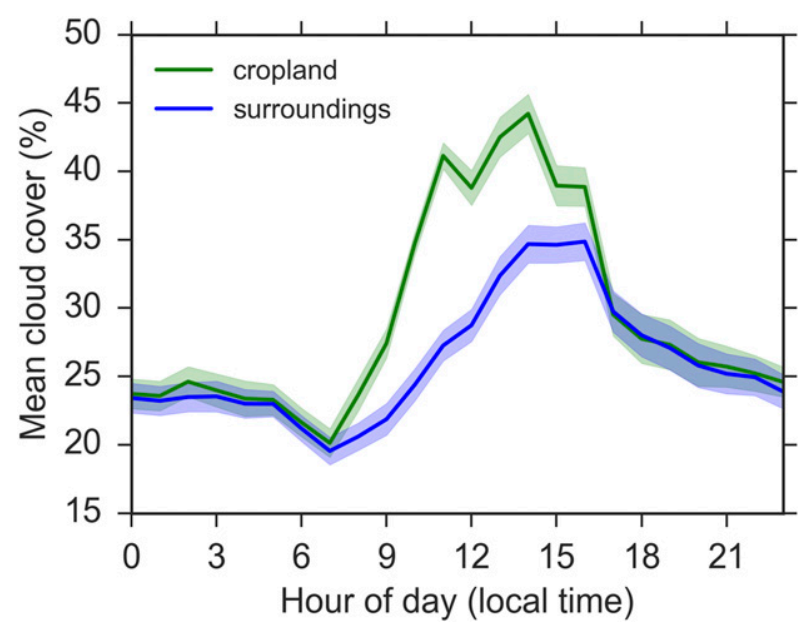

FIG. 5. Mean diurnal cycle of MAM cloud cover from SEVIRI for 2004-15 over the cropland (green) and the "surroundings," defined as the $25-\mathrm{km}$ boundary around the cropland (blue). The shaded area represents the standard error of the temporal average of monthly data. 


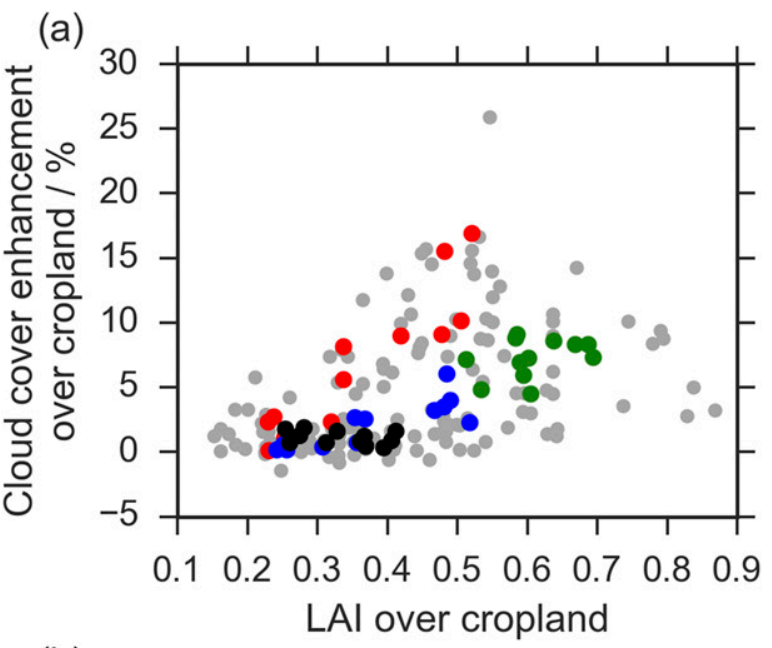

(b)
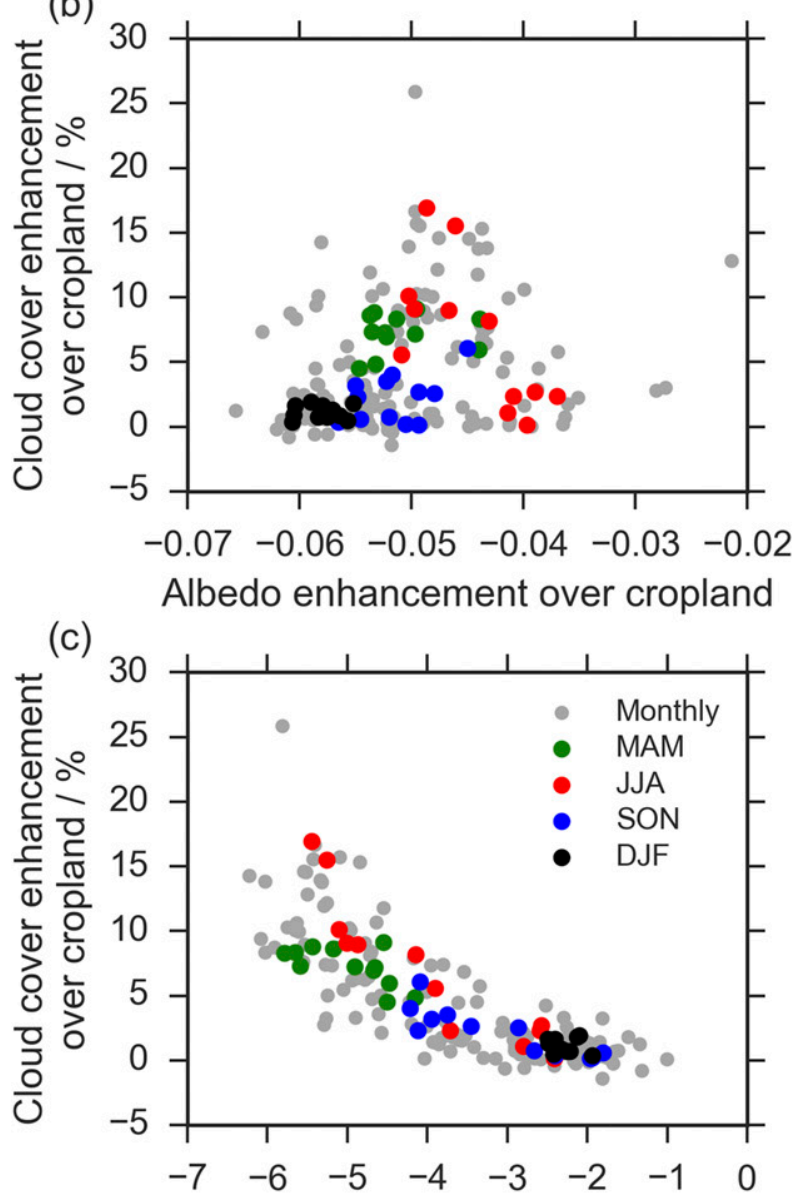

LST enhancement over cropland

FIG. 6. Scatterplot of interannual variability in daytime cloud fraction enhancement over the cropland region (from SEVIRI) and (a) LAI over the cropland, (b) albedo anomaly over the cropland, and (c) LST anomaly over the cropland (K; averaged for Terra and Aqua satellites). In all cases we show interannual monthly (gray) and seasonal (colors) values for 2004-15.

\section{Summary and discussion}

We have used satellite data to show a positive feedback between cropland and afternoon clouds in the arid Al-Jowf region in Saudi Arabia, linked to lower land surface temperatures that must be coupled to increased humidity over the cropland. The location of crops in this region is not linked to rainfall (which is very low), as crops are irrigated with nonrenewable groundwater resources, and their location in a valley suggests that any enhancement in clouds or rainfall cannot be attributed to orography.

The cropland is associated with $5-7-\mathrm{K}$ reductions in LST relative to its surroundings, despite having a slightly lower albedo, and which must therefore be accompanied by large increases in latent heat fluxes. Daytime cloud fractions over the cropland are on average higher by up to $15 \%$ points relative to the area surrounding the crops during the growing season (representing a relative increase of up to $60 \%$ ). This increase is associated with much more rapid cloud development in the morning, leading to a higher peak in cloud cover in the afternoon. Interannual variations in mean daytime cloud cover over the crops are highly correlated with LAI $(r=0.66, p<0.01)$, although the impact of LAI is higher during the summer months. The variability is mainly explained by changes in LST, which is linked to Bowen ratio $(r=0.88)$ as opposed to albedo $(r=0.29)$, and the higher sensitivity in summer is likely to be due to increased evaporation when conditions are warmer and drier. It is worth noting that although increased cloud cover could also reduce LST (inverting the causal chain), LST is only retrieved for cloud-free pixels and so is unlikely to explain our results.

While rainfall events are much rarer than cloud events generally (occurring on $\sim 1 \%$ of days), there is evidence from two different retrievals that rainfall is increased over, and around, the cropland, and this increase is caused by an increase in both the intensity and number of events. Given the relatively coarse spatial resolution of the rainfall datasets, and the low number of events, it is difficult to determine whether the rainfall is enhanced over the cropland itself (as with the cloud cover), or in the boundaries, as is observed in other regions. The change in rainfall represents an aggregated increase of $15 \mathrm{~mm} \mathrm{yr}^{-1}$ for each MAM period, which is approximately $2.5 \%$ of the seasonal crop water requirement for wheat in this region (Chowdhury et al. 2013).

The cloud feedback sign we observe here is the opposite to that found over moist tropical and semiarid regions, where clouds are typically enhanced over the 
(a)
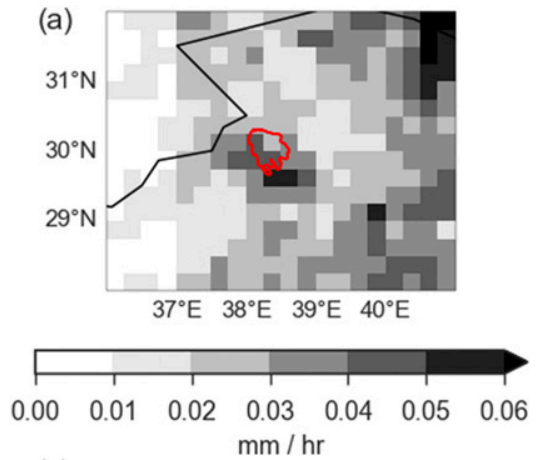

(c)
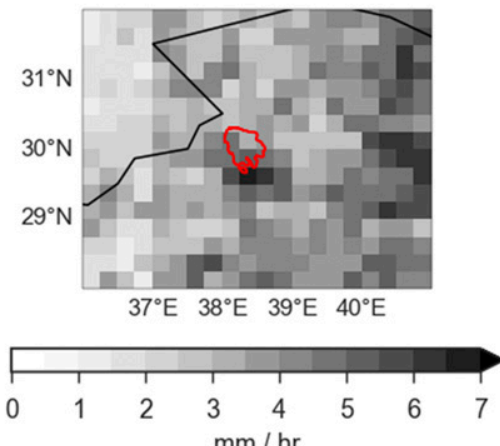

(b)
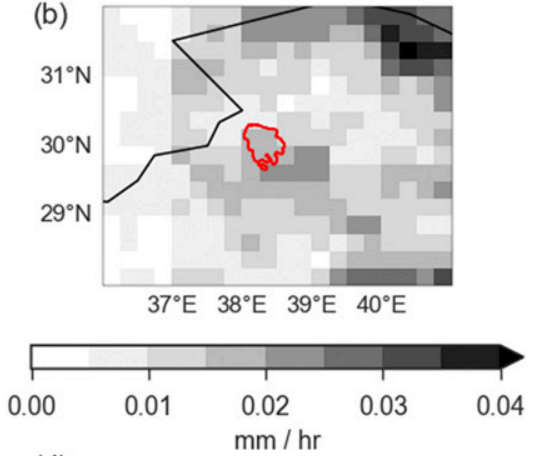

(d)
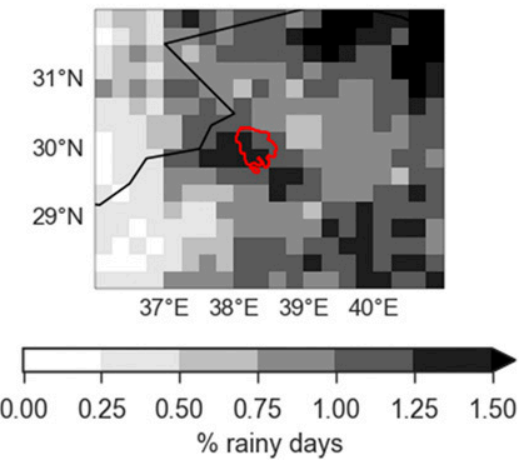

FIG. 7. Mean TRMM rainfall for MAM for 1998-2016 in the (a) afternoon (1400-1700 LT) and (b) night (0200-1100 LT), (c) mean afternoon rainfall intensity when it rains, and (d) percentage of days with afternoon rainfall exceeding $1 \mathrm{~mm} \mathrm{~h}^{-1}$.

less vegetated, warmer, and drier side of land-type discontinuities, due to convergence produced by "vegetation" breezes (Wang et al. 2009; Garcia-Carreras et al. 2010; Knox et al. 2011). The low-level temperature gradients between irrigated land and desert are likely to be even larger than in moister regions, but it is possible that our results differ because strong daytime dry convection associated with high surface heating mixes out any land-surface-induced breezes, reducing the importance of LST gradients. For example, dry convection has been shown to suppress the monsoon flow in Africa (Parker et al. 2005) and prevent the propagation of the "Atlantic inflow" sea breeze into the Sahara during the day (Grams et al. 2010). This is consistent with aircraft observations showing dry convective updrafts of up to $10 \mathrm{~m} \mathrm{~s}^{-1}$ in the Sahara (Garcia-Carreras et al. 2015), while horizontal flows associated with an LST anomaly of $5 \mathrm{~K}$ would be no more than $3 \mathrm{~m} \mathrm{~s}^{-1}$ (Dixon et al. 2013).

From a 1D perspective there can be either a wet-soil or dry-soil advantage to cloud formation, depending on the initial profile (Findell and Eltahir 2003). Drier soils lead to a deeper boundary layer, while a wetter surface lowers the lifting condensation level, both effects that could promote cloud formation. In the dry extreme there must be a wet advantage, as some moisture is required for clouds to form, but even without reaching this extreme, if the boundary layer is entraining very dry air as it grows, it is possible that the impact of moisture dominates. Finally, the results here suggest that the boundary layer equivalent potential temperature, which is closely tied to CAPE, is higher over the cropland, which is consistent with the cloud enhancement we observe [as also seen in Garcia-Carreras et al. (2011)]. In summary, while there is currently no universal theory for which surface is dominant, results from our paper show clouds favored over a wet surface in this environment, providing an important part of the phase space to assess in future modeling and theoretical studies. Additional modeling work, or in situ data, will be required to understand the balance of processes in such arid environments and address the hypotheses raised here.

Changes in cloud cover over the crop are important as they are likely to have a positive impact on crop development. Cloud shading in the middle of the day, when solar insolation is strongest, will reduce temperatures over the crops, thus reducing both temperature stress and agricultural water demand. While the change in LST due to enhanced evaporation will probably have a larger impact on temperatures than cloud shading, models are likely to capture the change in LST due to irrigation to at least some degree, while they struggle to capture even the sign of the land surface feedback on clouds. 

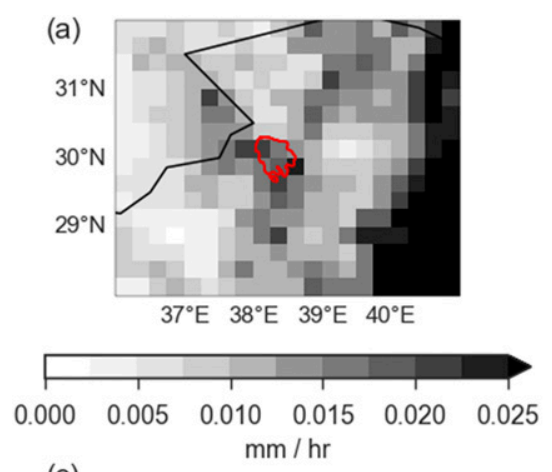

(c)
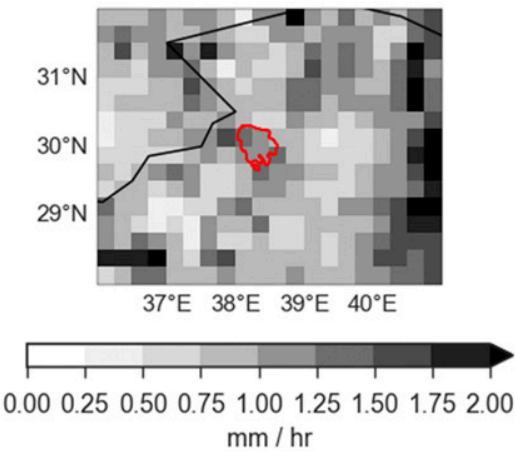

(b)
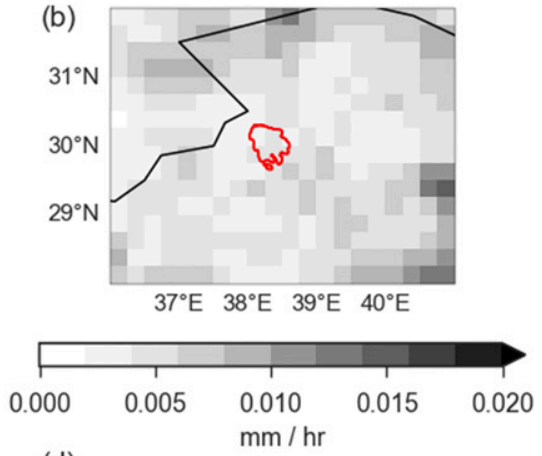

(d)
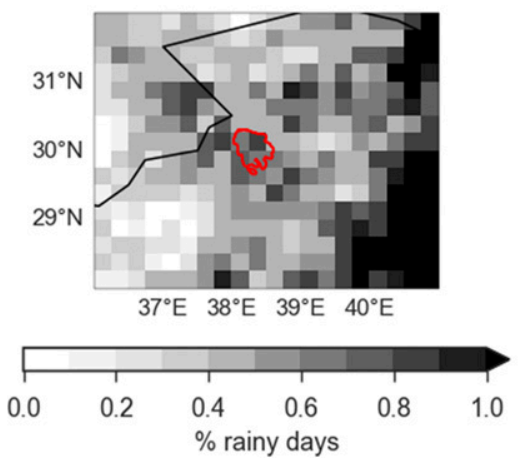

FIG. 8. As in Fig. 7, but for the CMORPH retrieval for 2002-16.

Photosynthesis also responds more efficiently to diffuse, compared to direct, radiation, particularly when radiation levels are high overall (Gu et al. 2002; Oliveira et al. 2007). The effects of enhanced cloud cover over the cropland on both temperature and radiation will therefore act to enhance crop productivity, producing a positive feedback, although quantifying the extent of this feedback is beyond the scope of this paper. Enhanced cloud shading over the crops could therefore reduce the anticipated detrimental effects of climate change, which are mainly linked to temperature stress (Chowdhury et al. 2013). Anticipated increases in crop water requirements due to climate change (Chowdhury et al. 2013) could also be overpredicted, which could affect the planning of how the limited nonrenewable groundwater resources in the area will be managed. These effects are unlikely to be captured by global climate models, which have grid boxes larger than the entire cropland region and struggle to accurately represent land-atmosphere feedbacks (Taylor et al. 2012).

The impact of the vegetation on rainfall is likely to have a small direct impact in the region discussed in this paper, as the aggregated seasonal rainfall increase over the crops only contributes a small percentage of the crop water requirements, but it could be important for other revegetation projects that are less reliant on irrigation. Enhanced rainfall over newly planted vegetation could produce a positive feedback, promoting further vegetation regrowth and rainfall, increasing the likelihood of a positive outcome for such projects.

While this study provides evidence of a positive vegetation-cloud feedback in arid environments, further work is needed to describe in detail the mechanisms responsible, both with atmospheric models and, ideally, in situ observations, as has been done more extensively for tropical environments. This would help understand exactly what environmental conditions allow certain feedbacks to occur, and so allow a better quantification of the effects of global land-use change on climate. For example, the Great Green Wall for the Sahara and Sahel Initiative lies in a semiarid strip between tropical forest in the south and the Sahara Desert in the north, and so it is unclear if rainfall would be enhanced or suppressed over the newly planted vegetation and what the impact of these feedbacks would be on the long-term viability of the project.

Acknowledgments. Marsham and Spracklen are supported by the Natural Environment Research Council (NERC) VERA project NE/M003574/1. The MOD11C3, MYD11C3, and MCD43C3 products were retrieved from the online Data Pool, courtesy of the NASA EOSDIS Land Processes Distributed Active Archive Center (LP DAAC), USGS/Earth Resources Observation and 
Science (EROS) Center, Sioux Falls, South Dakota (https://lpdaac.usgs.gov/data_access/data_pool). SEVIRI cloud data were provided by EUMETSAT's Satellite Application Facility on Climate Monitoring (CM SAF; http://www.cmsaf.eu). TRMM rainfall data were provided by the Goddard Earth Sciences Data and Information Services Center (http://mirador.gsfc.nasa. gov). Leaf area index data were accessed from http:// globalchange.bnu.edu.cn/research/lai/. MODIS cloud fraction data were retrieved from the NASA Earth Observations website (http://neo.sci.gsfc.nasa.gov). CMORPH data were retrieved from the Research Data Archive at the National Center for Atmospheric Research (http://rda.ucar.edu/datasets/ds502.0/). We thank two anonymous reviewers and Christopher Taylor, whose reviews have greatly improved the clarity and content of the paper.

\section{REFERENCES}

Abdullah, K., 2006: Use of water and land for food security and environmental sustainability. Irrig. Drain., 55, 219-222, doi:10.1002/ird.254.

Alkolibi, F. M., 2002: Possible effects of global warming on agriculture and water resources in Saudi Arabia: Impacts and responses. Climatic Change, 54, 225-245, doi:10.1023/ A:1015777403153.

Almazroui, M., M. N. Islam, P. D. Jones, H. Athar, and M. A. Rahman, 2012: Recent climate change in the Arabian Peninsula: Seasonal rainfall and temperature climatology of Saudi Arabia for 1979-2009. Atmos. Res., 111, 29-45, doi:10.1016/ j.atmosres.2012.02.013.

Alter, R. E., E.-S. Im, and E. A. B. Eltahir, 2015: Rainfall consistently enhanced around the Gezira Scheme in East Africa due to irrigation. Nat. Geosci., 8, 763-767, doi:10.1038/ngeo2514.

Betts, A. K., and J. H. Ball, 1995: The FIFE surface diurnal cycle climate. J. Geophys. Res., 100, 25679-25693, doi:10.1029/ 94JD03121.

Cao, S., 2008: Why large-scale afforestation efforts in China have failed to solve the desertification problem. Environ. Sci. Technol., 42, 1826-1831, doi:10.1021/es0870597.

Chowdhury, S., M. Al-Zahrani, and A. Abbas, 2013: Implications of climate change on crop water requirements in arid region: An example of Al-Jouf, Saudi Arabia. J. King Saud Univ., Eng. Sci., 28, 21-31, doi:10.1016/j.jksues.2013.11.001.

Dai, A., 2013: Increasing drought under global warming in observations and models. Nat. Climate Change, 3, 52-58, doi:10.1038/nclimate1633.

DeAngelis, A., F. Dominguez, Y. Fan, A. Robock, M. D. Kustu, and D. Robinson, 2010: Evidence of enhanced precipitation due to irrigation over the Great Plains of the United States. J. Geophys. Res., 115, D15115, doi:10.1029/2010JD013892.

Dixon, N. S., D. J. Parker, C. M. Taylor, L. Garcia-Carreras, P. P. Harris, J. H. Marsham, J. Polcher, and A. Woolley, 2013: The effect of background wind on mesoscale circulations above variable soil moisture in the Sahel. Quart. J. Roy. Meteor. Soc., 139, 1009-1024, doi:10.1002/qj.2012.

Döll, P., and S. Siebert, 2002: Global modeling of irrigation water requirements. Water Resour. Res., 38, 1037, doi:10.1029/ 2001WR000355.
Douglas, E. M., A. Beltrán-Przekurat, D. Niyogi, R. A. Pielke Sr., and C. J. Vörösmarty, 2009: The impact of agricultural intensification and irrigation on land-atmosphere interactions and Indian monsoon precipitation-A mesoscale modeling perspective. Global Planet. Change, 67, 117-128, doi:10.1016/ j.gloplacha.2008.12.007.

Findell, K. L., and E. A. B. Eltahir, 2003: Atmospheric controls on soil moisture-boundary layer interactions. Part I: Framework development. J. Hydrometeor., 4, 552-569, doi:10.1175/ 1525-7541(2003)004<0552:ACOSML>2.0.CO;2.

Finkensieper, S., and Coauthors, 2016: CLAAS-2: CM SAF CLoud property dAtAset using SEVIRI-Edition 2. Satellite Application Facility on Climate Monitoring, accessed November 29, 2016, doi:10.5676/EUM_SAF_CM/ CLAAS/V002.

Garcia-Carreras, L., and D. J. Parker, 2011: How does local tropical deforestation affect rainfall? Geophys. Res. Lett., 38, L19802, doi:10.1029/2011GL049099.

- — C. M. Taylor, C. E. Reeves, and J. G. Murphy, 2010: Impact of mesoscale vegetation heterogeneities on the dynamical and thermodynamic properties of the planetary boundary layer. J. Geophys. Res., 115, D03102, doi:10.1029/ 2009JD012811.

_, - and J. H. Marsham, 2011: What is the mechanism for the modification of convective cloud distributions by land surface-induced flows? J. Atmos. Sci., 68, 619-634, doi:10.1175/2010JAS3604.1.

, and Coauthors, 2015: The turbulent structure and diurnal growth of the Saharan atmospheric boundary layer. J. Atmos. Sci., 72, 693-713, doi:10.1175/JAS-D-13-0384.1.

General Authority for Statistics, 2012: Saudi Statistical Year Book. Ministry of Economy and Planning, Central Department of Statistics and Information, accessed 15 May 2015. [Available online at https://www.stats.gov.sa/sites/all/modules/pubdlcnt/ pubdlcnt.php?file=https://www.stats.gov.sa/sites/default/files/ yb48.zip\&nid=3719.]

Grams, C., S. Jones, J. Marsham, D. Parker, J. Haywood, and V. Heuveline, 2010: The Atlantic inflow to the Saharan heat low: Observations and modelling. Quart. J. Roy. Meteor. Soc., 136, 125-140, doi:10.1002/qj.429.

Gu, L., D. Baldocchi, S. B. Verma, T. A. Black, T. Vesala, E. M. Falge, and P. R. Dowty, 2002: Advantages of diffuse radiation for terrestrial ecosystem productivity. J. Geophys. Res., 107, 4050, doi:10.1029/2001JD001242.

Harding, K. J., and P. K. Snyder, 2012: Modeling the atmospheric response to irrigation in the Great Plains. Part I: General impacts on precipitation and the energy budget. J. Hydrometeor., 13, 1667-1686, doi:10.1175/JHM-D-11-098.1.

Huang, Q., J. H. Marsham, D. J. Parker, W. Tian, and T. Weckwerth, 2009: A comparison of roll and nonroll convection and the subsequent deepening moist convection: An LEM case study based on SCMS data. Mon. Wea. Rev., 137, 350-365, doi:10.1175/2008MWR2450.1.

Huffman, G. J., and Coauthors, 2007: The TRMM Multisatellite Precipitation Analysis (TMPA): Quasi-global, multiyear, combined-sensor precipitation estimates at fine scales. J. Hydrometeor., 8, 38-55, doi:10.1175/JHM560.1.

Kawase, H., T. Yoshikane, M. Hara, F. Kimura, T. Sato, and S. Ohsawa, 2008: Impact of extensive irrigation on the formation of cumulus clouds. Geophys. Res. Lett., 35, L01806, doi:10.1029/2007GL032435.

Kealy, J. C., F. Marenco, J. H. Marsham, L. Garcia-Carreras, P. N. Francis, M. C. Cooke, and J. Hocking, 2017: Clouds over the 
summertime Sahara: An evaluation of Met Office Meteosat retrievals using airborne remote sensing. Atmos. Chem. Phys., 17, 5789-5807, doi:10.5194/acp-17-5789-2017.

Knox, R., G. Bisht, J. Wang, and R. Bras, 2011: Precipitation variability over the forest-to-nonforest transition in southwestern Amazonia. J. Climate, 24, 2368-2377, doi:10.1175/ 2010JCLI3815.1.

Kueppers, L. M., and M. A. Snyder, 2012: Influence of irrigated agriculture on diurnal surface energy and water fluxes, surface climate, and atmospheric circulation in California. Climate Dyn., 38, 1017-1029, doi:10.1007/s00382-011-1123-0.

Marsham, J. H., D. J. Parker, C. M. Grams, B. T. Johnson, W. M. F. Grey, and A. N. Ross, 2008: Observations of mesoscale and boundary-layer scale circulations affecting dust transport and uplift over the Sahara. Atmos. Chem. Phys., 8, 6979-6993, doi:10.5194/acp-8-6979-2008.

Mekonnen, M. M., and A. Y. Hoekstra, 2011: The green, blue and grey water footprint of crops and derived crop products. Hydrol. Earth Syst. Sci., 15, 1577-1600, doi:10.5194/hess-15-1577-2011.

Oliveira, P. H. F., and Coauthors, 2007: The effects of biomass burning aerosols and clouds on the $\mathrm{CO}_{2}$ flux in Amazonia. Tellus, 59B, 338-349, doi:10.1111/j.1600-0889.2007.00270.x.

Parker, D. J., and Coauthors, 2005: The diurnal cycle of the West African monsoon circulation. Quart. J. Roy. Meteor. Soc., 131, 2839-2860, doi:10.1256/qj.04.52.

Pielke, R. A., and Coauthors, 2011: Land use/land cover changes and climate: Modeling analysis and observational evidence. Wiley Interdiscip. Rev: Climate Change, 2, 828-850, doi:10.1002/wcc.144.

Puma, M. J., and B. I. Cook, 2010: Effects of irrigation on global climate during the 20th century. J. Geophys. Res., 115, D16120, doi:10.1029/2010JD014122.

Ramankutty, N., A. T. Evan, C. Monfreda, and J. A. Foley, 2008: Farming the planet: 1. Geographic distribution of global agricultural lands in the year 2000. Global Biogeochem. Cycles, 22, GB1003, doi:10.1029/2007GB002952.

Reuter, M., W. Thomas, P. Albert, M. Lockhoff, R. Weber, K.-G. Karlsson, and J. Fischer, 2009: The CM-SAF and FUB cloud detection schemes for SEVIRI: Validation with synoptic data and initial comparison with MODIS and CALIPSO. J. Appl. Meteor. Climatol., 48, 301-316, doi:10.1175/ 2008JAMC1982.1.

Roy, S. B., 2009: Mesoscale vegetation-atmosphere feedbacks in Amazonia. J. Geophys. Res., 114, D20111, doi:10.1029/ 2009JD012001.

Sato, T., F. Kimura, and A. S. Hasegawa, 2007: Vegetation and topographic control of cloud activity over arid/semiarid Asia. J. Geophys. Res., 112, D24109, doi:10.1029/2006JD008129.

Schaaf, C., and Z. Wang, 2015: MCD43C3 MODIS/Terra+Aqua BRDF/Albedo Daily L3 Global 0.05Deg CMG V006. NASA EOSDIS Land Processes DAAC, accessed 20 June 2016, doi:10.5067/MODIS/MCD43C3.006.
— , and Coauthors, 2002: First operational BRDF, albedo nadir reflectance products from MODIS. Remote Sens. Environ., 83, 135-148, doi:10.1016/S0034-4257(02)00091-3.

Sheffield, J., and E. F. Wood, 2008: Projected changes in drought occurrence under future global warming from multi-model, multi-scenario, IPCC AR4 simulations. Climate Dyn., 31, 79-105, doi:10.1007/s00382-007-0340-z.

Spracklen, D. V., and L. Garcia-Carreras, 2015: The impact of Amazonian deforestation on Amazon basin rainfall. Geophys. Res. Lett., 42, 9546-9552, doi:10.1002/2015GL066063.

_ S. R. Arnold, and C. M. Taylor, 2012: Observations of increased tropical rainfall preceded by air passage over forests. Nature, 489, 282-285, doi:10.1038/nature11390.

Taylor, C. M., R. A. M. de Jeu, F. Guichard, P. P. Harris, and W. A. Dorigo, 2012: Afternoon rain more likely over drier soils. Nature, 489, 423-426, doi:10.1038/nature11377.

Tilman, D., 2001: Forecasting agriculturally driven global environmental change. Science, 292, 281-284, doi:10.1126/ science.1057544.

Wada, Y., L. P. H. van Beek, and M. F. P. Bierkens, 2012: Nonsustainable groundwater sustaining irrigation: A global assessment. Water Resour. Res., 48, W00L06, doi:10.1029/ 2011WR010562.

Wan, Z., 2014: New refinements and validation of the collection-6 MODIS land-surface temperature/emissivity product. Remote Sens. Environ., 140, 36-45, doi:10.1016/j.rse.2013.08.027.

_- S. Hook, and G. Hulley, 2015a: MYD11C3 MODIS/Aqua Land Surface Temperature/Emissivity Monthly L3 Global 0.05Deg CMG V006. NASA EOSDIS Land Processes DAAC, accessed 14 December 2016, doi:10.5067/MODIS/ MYD11C3.006.

—_ - - , and —_, 2015b: MOD11C3 MODIS/Terra Land Surface Temperature/Emissivity Monthly L3 Global 0.05Deg CMG V006. NASA EOSDIS Land Processes DAAC, accessed 14 December 2016, doi:10.5067/MODIS/ MOD11C3.006.

Wang, J., and Coauthors, 2009: Impact of deforestation in the Amazon basin on cloud climatology. Proc. Natl. Acad. Sci. USA, 106, 3670-3674, doi:10.1073/pnas.0810156106.

Wang, X. M., C. X. Zhang, E. Hasi, and Z. B. Dong, 2010: Has the Three Norths Forest Shelterbelt Program solved the desertification and dust storm problems in arid and semiarid China? J. Arid Environ., 74, 13-22, doi:10.1016/ j.jaridenv.2009.08.001.

Woodfine, A., and S. Jauffret, 2009: Scope and pre-feasibility study on the Great Green Wall for the Sahara and Sahel Initiative. Tech. Rep., 57 pp. [Available online at http://www.fao.org/3/ a-ax353e.pdf.]

Yuan, H., Y. Dai, Z. Xiao, D. Ji, and W. Shangguan, 2011: Reprocessing the MODIS leaf area index products for land surface and climate modelling. Remote Sens. Environ., 115, 1171-1187, doi:10.1016/j.rse.2011.01.001. 